\title{
Effect of $\mathrm{Si}$ on $\mathrm{Ti} / \mathrm{Al}$ brittle interfacial phases and microstructural evolution of pulsed current gas tungsten arc welding joints
}

\author{
K. Liu, Y. Li*, J. Wang, S. Wei, Y. Zhou \\ Key Laboratory for Liquid-Solid Structural Evolution and Processing of Materials (Ministry of Education), \\ Shandong University, Jinan 250061, P. R. China
}

Received 15 January 2015, received in revised form 16 March 2015, accepted 16 April 2015

\begin{abstract}
The effect of Si on brittle interfacial phases and microstructural evolution of $\mathrm{Ti} / \mathrm{Al}$ joints was investigated during pulsed current gas tungsten arc welding (PCGTAW) with filler wires. Interfacial microstructure and phase constituents were characterized by an optical microscopy $(\mathrm{OM})$, X-ray diffraction (XRD), scanning electron microscope (SEM) and energy dispersive spectrometer (EDS). The microstructural evolution mechanism was revealed from the perspective of the thermodynamics. It was found that the layered microstructure consisted of various $\mathrm{Ti}-\mathrm{Al}$ or $\mathrm{Ti}-\mathrm{Si}$ intermetallic compounds (IMCs). The effect of silicon on the reaction mechanism of fusion-welding interface mainly included that the formation of $\mathrm{Ti}_{5} \mathrm{Si}_{3}$ consumed most molten titanium and suppressed the reaction of titanium with aluminum. Moreover, the $\mathrm{Ti}_{5} \mathrm{Si}_{3}$ distributing at the grain boundary contributed to the forming of discontinuous $\mathrm{TiAl}_{3}$. The effect of silicon on the reaction mechanism of brazed interface was mainly reflected by silicon in the reaction of titanium with aluminum and the forming of $\operatorname{Ti}\left(\mathrm{Al}_{x} \mathrm{Si}_{1-x}\right)_{3}$.
\end{abstract}

K e y w or d s: effect of $\mathrm{Si}$, interface, microstructural evolution, welding, Ti/ $\mathrm{Al}$

\section{Introduction}

Titanium and aluminum alloys have been widely applied in the field of aerospace and high-speed train, which attributes to their excellent properties such as low density, high strength to weight ratio and superior anti-corrosion [1-4]. The heterostructures of $\mathrm{Ti} / \mathrm{Al}$ light metals could achieve the aim of energy conservation and emission reduction, so it is very necessary to join titanium to aluminum [5]. However, significant differences in thermophysical and thermochemical performances of titanium and aluminum alloys result in challenges of obtaining reliable $\mathrm{Ti} / \mathrm{Al}$ dissimilar joints. The formation of interfacial brittle intermetallic compounds is a key problem while joining $\mathrm{Ti} / \mathrm{Al}$ [6].

Previous research works on the joining of $\mathrm{Ti} / \mathrm{Al}$ have been reported $[3,4,7-9]$. Some conventional fusion welding methods are not suitable for joining $\mathrm{Ti} / \mathrm{Al}$. Chen et al. [10] pointed out that the temperature gradient along the interface influenced interfacial reaction and adopted rectangular spot laser beam to improve homogenization of $\mathrm{Ti} / \mathrm{Al}$ interfacial reaction. Dressler et al. [4] investigated the feasibility of friction stir welding $\mathrm{Ti} / \mathrm{Al}$ dissimilar alloys by shifting the tool pin center toward the aluminum plate. Furthermore, adding appropriate filler metals or adjusting the heat input was an effective way to improve interfacial microstructure during fusion welding of $\mathrm{Ti} / \mathrm{Al}$. Liu et al. [11] selected Al-5Si (ER4043) aluminum alloy as filler wire to obtain $\mathrm{Ti} / \mathrm{Al}$ gas tungsten arc welding (GTAW) joints and divided the reaction zone at the top of joints into three morphology layers with numerous granular precipitations. Also, Wei et al. [12] proposed two kinds of cracks near $\mathrm{Ti} / \mathrm{Al}$ interface of tungsten inert gas (TIG) welding joints and pointed out that preference propagation paths of cracks are along the interfaces between different intermetallic layers or cross micro-defects near $\mathrm{Ti} / \mathrm{Al}$ interface. However, few reports about the effect of alloying elements (especially $\mathrm{Si}$ ) on the interfacial microstructural evolution have been published.

In the present work, pulsed current gas tungsten arc welding (PCGTAW) with Al-Si filler metals was

*Corresponding author: tel.: +86 13583136059; e-mail address: yajli@sdu.edu.cn 
Table 1. Chemical compositions of base metals and filler wires (wt.\%)

\begin{tabular}{lcccccccccccc}
\hline Materials & $\mathrm{Ti}$ & $\mathrm{Al}$ & $\mathrm{Cu}$ & $\mathrm{Mg}$ & $\mathrm{Mn}$ & $\mathrm{Fe}$ & $\mathrm{Si}$ & $\mathrm{Zn}$ & $\mathrm{Zr}$ & $\mathrm{V}$ & $\mathrm{Mo}$ \\
\hline TA15 & Bal. & 6.0 & - & - & - & - & - & - & 2.0 & 1.5 & 1.6 \\
2A12 & 0.15 & Bal. & 4.2 & 1.5 & 0.5 & 0.5 & 0.5 & 0.3 & - & - & - \\
ER4043 & - & Bal. & 0.2 & 0.05 & 0.05 & 0.7 & 5.0 & 0.10 & - & - & - \\
ER4047 & - & Bal. & 0.3 & 0.10 & 0.15 & 0.7 & 12.0 & 0.10 & - & - & - \\
\hline
\end{tabular}

Table 2. Physical properties of TA15 titanium alloy and 2A12 aluminum alloy

\begin{tabular}{|c|c|c|c|c|c|}
\hline Alloys & $\begin{array}{l}\text { Density } \\
\left(\mathrm{g} \mathrm{cm}^{-3}\right)\end{array}$ & $\begin{array}{l}\text { Melting point } \\
\left({ }^{\circ} \mathrm{C}\right)\end{array}$ & $\begin{array}{l}\text { Specific heat capacity } \\
\qquad\left(\mathrm{J} \mathrm{kg}^{-1} \mathrm{~K}^{-1}\right)\end{array}$ & $\begin{array}{l}\text { Coefficient of thermal conductivity } \\
\qquad\left(\mathrm{W} \mathrm{m}^{-1} \mathrm{~K}^{-1}\right)\end{array}$ & $\begin{array}{l}\text { Coefficient of linear expansion } \\
\qquad\left(10^{-6} \mathrm{~K}^{-1}\right)\end{array}$ \\
\hline TA15 & 4.45 & 1700 & 545 & 8.8 & 8.9 \\
\hline 2A12 & 2.78 & 570 & 921 & 117.2 & 22.7 \\
\hline
\end{tabular}

Ta ble 3. Welding parameters used for pulsed current GTAW

\begin{tabular}{cccccccc}
\hline \multirow{2}{*}{ Groups } & \multicolumn{6}{c}{ Welding parameters } \\
\cline { 2 - 8 } & $\begin{array}{c}\text { Voltage } \\
U(\mathrm{~V})\end{array}$ & $\begin{array}{c}\text { Base current } \\
I_{\mathrm{B}}(\mathrm{A})\end{array}$ & $\begin{array}{c}\text { Pulse current } \\
I_{\mathrm{P}}(\mathrm{A})\end{array}$ & $\begin{array}{c}\text { During ratio } \\
K(\%)\end{array}$ & $\begin{array}{c}\text { Pulse frequency } \\
f(\mathrm{~Hz})\end{array}$ & $\begin{array}{c}\text { Welding velocity } \\
v\left(\mathrm{~cm} \mathrm{~s}^{-1}\right)\end{array}$ & $\begin{array}{c}\text { Diameter of wires } \\
\Phi(\mathrm{mm})\end{array}$ \\
\hline ER4043 & 12 & 60 & 140 & 50 & 2 & 0.28 & 2.0 \\
ER4047 & 12 & 60 & 140 & 50 & 2 & 0.26 & 2.0 \\
\hline
\end{tabular}

employed to join $\mathrm{Ti} / \mathrm{Al}$. As is demonstrated, the model of microstructure evolution was established to clarify the influence of Si on the microstructure and interfacial reaction mechanism. Moreover, the formation of IMCs near the interface was explored from the view of thermodynamics.

\section{Experimental procedures}

TA15 titanium alloy and 2A12 aluminum alloy $(200 \mathrm{~mm} \times 50 \mathrm{~mm} \times 2.5 \mathrm{~mm})$ in the form of the sheet were used as base metals in this study. Given others' findings $[8,10]$ and our previous work $[11,12]$ reporting that $\mathrm{Al}-\mathrm{Si}$ alloy filler wires were effective in improving interface morphologies and obtaining good interfacial metallurgical bonding, two groups of $\mathrm{Al}-\mathrm{Si}$ alloys including ER4043 (AlSi5) and ER4047 (AlSi12) were selected as filler wires to explore the effect of Si content on interfacial reaction mechanism. Chemical compositions of candidate materials and physical properties of base metals are presented in Table 1 and Table 2, respectively.

To remove the oxidation films and improve the interfacial wetting ability of liquid filler metal, the surface of base metals was cleaned prior to the welding process. TA15 alloy specimens were soaked in acetone for $3 \mathrm{~min}$, in acidic solution $\left(\mathrm{HNO}_{3} 20 \mathrm{vol} . \%\right.$, $\mathrm{HF} 2$ vol. $\%, \mathrm{H}_{2} \mathrm{O} 78$ vol.\%) for $5 \mathrm{~min}$ and in clear water for $5 \mathrm{~min}$, respectively. 2A12 aluminum alloy speci-

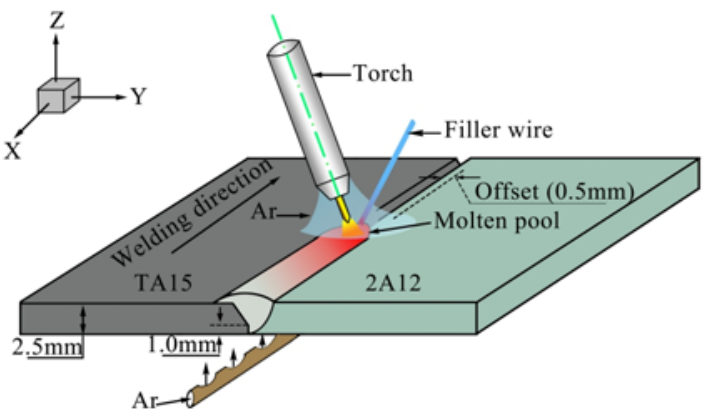

Fig. 1. Schematic of the pulse current GTAW process.

mens were soaked in acetone for $3 \mathrm{~min}$, in alkali liquor ( $\mathrm{NaOH} 8$ vol.\%, $\mathrm{H}_{2} \mathrm{O} 92$ vol.\%) for $5 \mathrm{~min}$ and in clear water for $5 \mathrm{~min}$, respectively. After cleaning the surface, all specimens were dried at $100^{\circ} \mathrm{C}$ for $30 \mathrm{~min}$.

The joint was arranged in the shape of "Y" groove with a bevel angle of $30^{\circ}$ in titanium side, which can enhance the interface wettability and promote the uniform interfacial reaction. Previous work has already shown that the interfacial morphologies could be improved by adopting the pulse current gas tungsten arc welding (PCGTAW) [12-14]. So the pulse current GTAW was carried out using the WSE-250 PCGAT welding machine with $2.4 \mathrm{~mm}$ diameter of the tungsten electrode. The schematic of PCGTAW process and detailed welding parameters are shown in Fig. 1 and Table 3, respectively. Also, two channels for Argon 

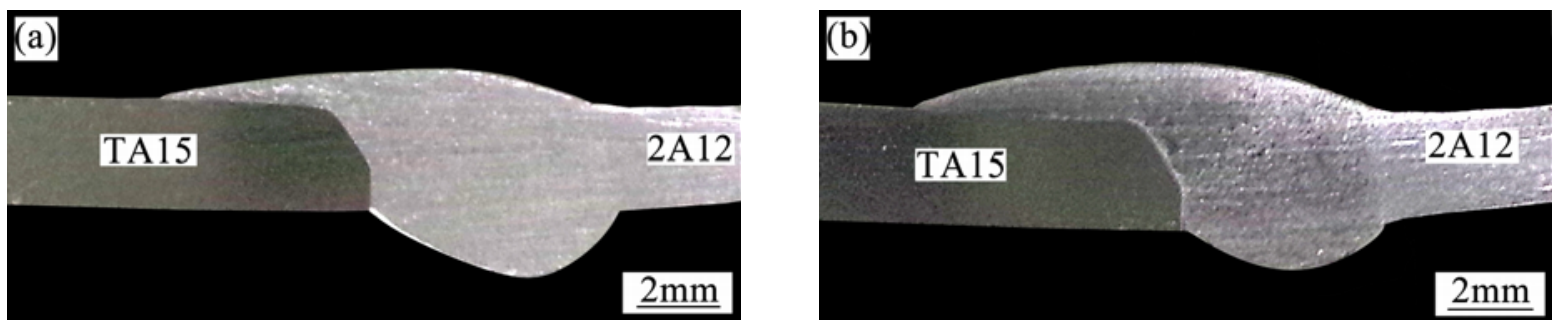

Fig. 2. Macrostructure on the cross-section of Ti/Al pulse current GTAW joints: (a) with ER4043 filler wire; (b) with ER4047 filler wire.

shielding gas were carefully designed to obtain sufficient protective effects; one was provided by a coaxial gas nozzle with a flow rate of $12 \mathrm{~L} \mathrm{~min}^{-1}$, another one was supplied using a porous tube with $18 \mathrm{~L} \mathrm{~min}^{-1}$ flow rate for back shielding. The offset of tungsten electrode toward aluminum base metal was set as $0.5 \mathrm{~mm}$ so as to reduce the fusion of titanium alloy and suppress the formation of numerous Ti-Al IMCs.

After welding, a typical cross-section of the joint was cut. In this study, standard grinding and polishing procedures were used. The metallographic samples were polished to a mirror-like surface aspect and etched with a mixed solution (14.3 vol.\% $\mathrm{HF}+$ 14.3 vol. $\% \mathrm{HNO}_{3}+71.4$ vol. $\left.\% \mathrm{H}_{2} \mathrm{O}\right)$. The macrostructure of $\mathrm{Ti} / \mathrm{Al}$ interface was observed by an optical microscope (OM). Microstructure examination and phase identification near the interface reaction layer were carried out by SU-70 (HITACHI) scanning electron microscope (SEM) with secondary electron mode and XRD (Rigaku D/MAX-rC), respectively. The EDS line mapping analysis on the etched samples was carried out with EX-250 (HORIBA) energy-dispersive $\mathrm{X}$-ray spectroscopy to infer the elemental migration across the interface.

\section{Results}

\subsection{Macrostructure of joints}

Figure 2 shows the cross-section feature of $\mathrm{Ti} / \mathrm{Al}$ joints. The good bonding was obtained in all two groups. The liquid filler metal spread on the partial top surface and all butt face of titanium alloy. A circle arc transition was formed at the bottom of joint. The aluminum alloy was molten and mixed with liquid metal to form the typical fusion welding. However, the content of alloying elements in filler metals has a significant effect on the quality of weld forming. Compared the appearance of joints with two kinds of Al-Si alloy filler wires, it was found that the filler wires with a high content of silicon element contributed to obtaining more smooth transition of joint and good wettability of liquid metal on the titanium alloy, as exhibited in Fig. 2b. The relationship between interfacial tension and wetting angle can be described by the following equation $[15,16]$ :

$$
\sigma_{\mathrm{s}-\mathrm{g}}-\sigma_{\mathrm{s}-1}=\sigma_{\mathrm{l}-\mathrm{g}} \cos \theta
$$

where $\sigma_{\mathrm{s}-\mathrm{g}}$ is the interfacial tension between solid and gas, $\sigma_{\mathrm{s}-1}$ is the interfacial tension between solid and liquid, $\sigma_{l-g}$ is the interfacial tension between liquid and gas, $\theta$ is the wetting angle.

\subsection{Ti/Al interfacial morphologies and phase constituents}

Due to adopting the pulsed current during GTA welding, the interfacial reaction may be very complex. To investigate the morphologies of the $\mathrm{Ti} / \mathrm{Al}$ interface in details, SEM analysis of microstructure was conducted. The SEM images of $\mathrm{Ti} / \mathrm{Al}$ interface microstructure are shown in Fig. 3. The layered microstructure was formed due to the reaction between the liquid mixed metal and some molten titanium. Especially in the fusion welding zone, the reaction zone consists of several layers despite the different content of silicon, as shown in Fig. 3a,c. Substantial $\mathrm{Ti}-\mathrm{Al}$ IMCs were formed near the interface reaction layer with the discontinuous distribution. Some bright micro-particles distributed on the gray IMCs in the case of the low content of silicon while Al-Si eutectic microstructure was formed in the grain boundary near the interface in the case of the high content of silicon. However, from Fig. 3b,d, it can be seen that the brazed interface displays different microstructural characteristics: a thin layer between titanium and weld metal. An obvious difference between fusionwelding interface and brazed interface is the number of IMCs.

The XRD result of the interface is shown in Fig. 4. It can be seen that phases of interface consist of $\mathrm{Ti}, \mathrm{Al}$, $\mathrm{TiAl}_{3}$. Ti-Al IMCs in different morphologies are major phases in the interface. Because of the less number of $\mathrm{TiAl}$ and $\mathrm{Ti}_{5} \mathrm{Si}_{3}$, they were not identified in the pattern. So it is necessary to use EDS analysis to characterize qualitatively the elements distribution near the interface. Also, since the interfacial reaction was sensitive to the thermal cycle [8], the only microstructure analysis is not sufficient to clarify the effect of silicon content on the interfacial reaction mechanism. 

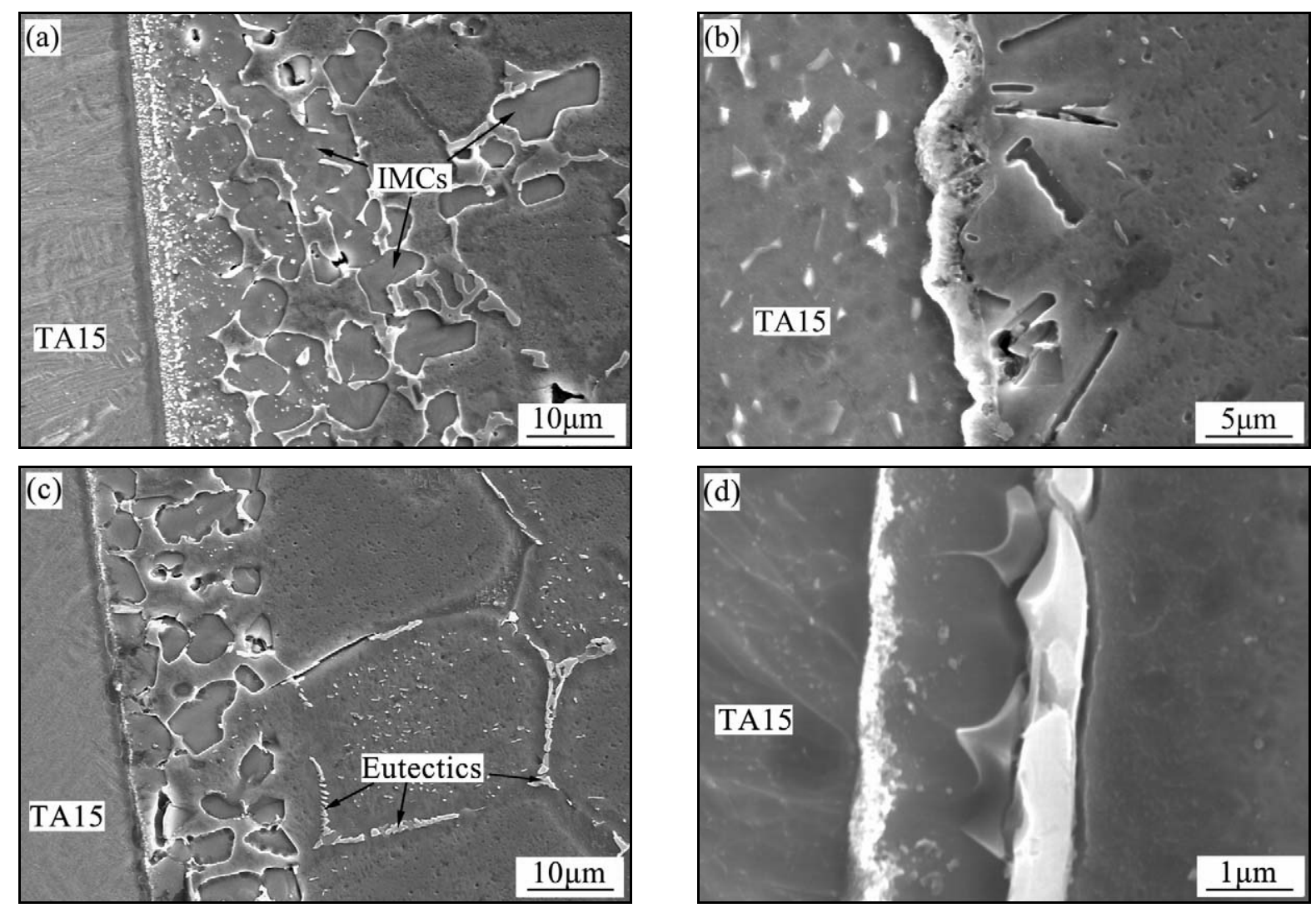

Fig. 3. SEM images of Ti/Al interface microstructure: (a) the fusion-welding zone in the case of ER4043 filler wire; (b) the brazed interface in the case of ER4043 filler wire; (c) the fusion-welding zone in the case of ER4047 filler wire; (d) the brazed interface in the case of ER4047 filler wire.

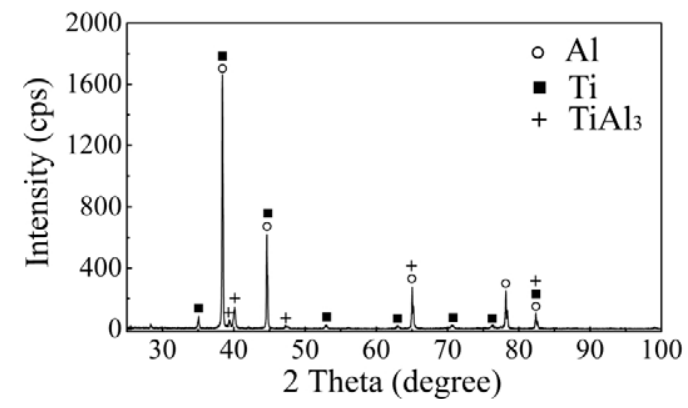

Fig. 4. XRD patterns of interface zone on the cross-section.

It is needed to analyze the composition of interfacial IMCs.

Interfacial reactions during microstructure evolution were very complex, which included solidification and solid-state phase transformation. Various microstructure morphologies are shown in Fig. 5a. According to morphological characterization, interfacial microstructure was divided into three reaction layers that are shown in Fig. 5b. The solidification process of each reaction layer was different. Composition content and phase constituents in reaction layers were analyzed by EDS composition analysis on spot 1 and
2 in Fig. 5b and the results are shown in Fig. 5c,d. The reaction layer (I) close to titanium alloys side is a thin continuous layer, which has a fine grain size and continuous compact microstructure. In the process of welding, bits of molten titanium reacted with aluminum and silicon diffusing from the molten pool under high temperature. Silicon reacted with titanium to form $\mathrm{Ti}_{5} \mathrm{Si}_{3}$ phase [6]. The blocky microstructure was distributed in the reaction (II). White particles $\mathrm{Ti}_{5} \mathrm{Si}_{3}$ are in centralized distribution around the grain boundary. The content of titanium is similar to that of aluminum in layer (II). From our previous phase identification, the reaction layer (II) was mainly composed of TiAl phase. Interfacial reaction layer (III) adjacent to weld metal is thicker and appears discontinuously serrated. A large number of serrated $\mathrm{TiAl}_{3}$ IMCs were formed and grew into weld metal. Because of rapid cooling rate, it was difficult for silicon replacing the lattice of aluminum in $\mathrm{TiAl}_{3}$ to escaping so solid solubility of silicon in $\mathrm{TiAl}_{3}$ phase reached as high as 5.79 at.\%.

There is a dependence of interfacial microstructure on silicon content. In the case of the higher content of silicon, the interfacial microstructure is shown in Fig. 6. The thickness of interface layer is thinner compared with that of joint with lower silicon content. 

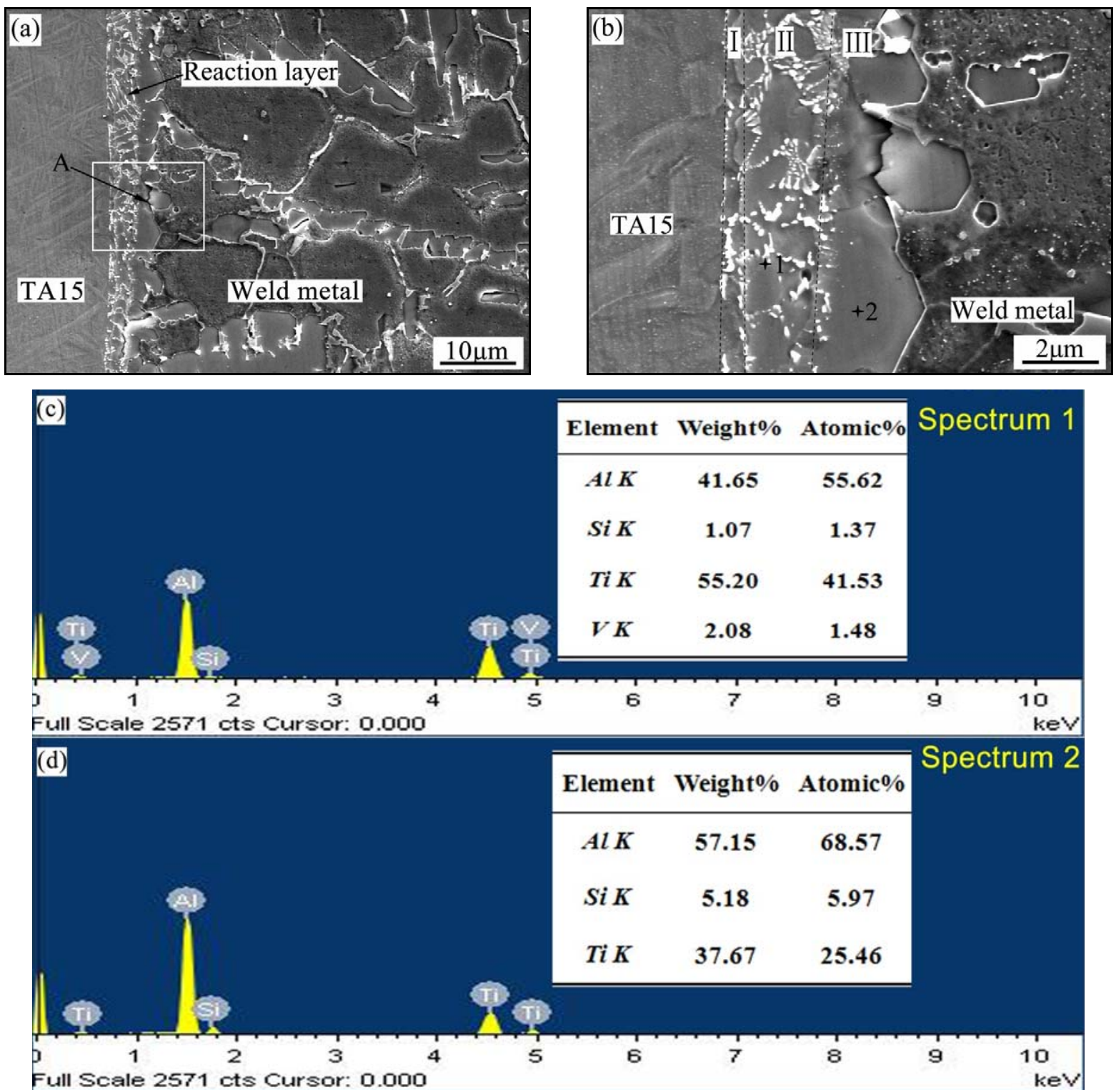

Fig. 5. EDS spot analysis near Ti/Al interface with ER4043 filler wire: (a) layered microstructure; (b) magnified area A marked in (a); (c) result of spot 1 ; (d) result of spot 2.

On the basis of atom amount ratio of titanium to aluminum in the result of EDS analysis on points 1 and 2 , from binary Ti-Al phase diagram, it could be deduced that intermetallic compounds are $\mathrm{TiAl}_{3}$. In $\mathrm{TiAl}_{3}$ IMCs, some aluminum atoms are substituted by silicon atoms to form $\operatorname{Ti}\left(\mathrm{Al}_{x} \mathrm{Si}_{1-x}\right)_{3}$. The serrated $\operatorname{Ti}\left(\mathrm{Al}_{x} \mathrm{Si}_{1-x}\right)_{3}$ has a growth direction perpendicular to the interface, which attributes to the distribution of temperature gradient and heat conduction.

\section{Discussion}

The result of EDS line scanning across the fusionwelding interface is shown in Fig. 7a,b. Intermetal- lic compounds are complicated because the interfacial reaction is complex after titanium alloy melting. The content of the aluminum element in intermetallic compounds varies in a certain degree. Most silicon element mainly reacted with titanium to form $\mathrm{Ti}_{5} \mathrm{Si}_{3}$ phase, so the distribution of silicon near the interface varies in a fluctuation, not in a stable range. The result of EDS line scanning across $\mathrm{Ti} / \mathrm{Al}$ brazed interface is shown in Fig. 7c,d. It is sure that elements of titanium, aluminum, silicon and vanadium diffused across the interface. From element distribution curve, the distribution trend of titanium and aluminum elements is obvious. Distribution of titanium element appears downtrend from heat affected zone to interface and platform appears near the interface. In serrated IMCs, the content of $\mathrm{Ti}$ is stable and homogeneous. In weld metal, 

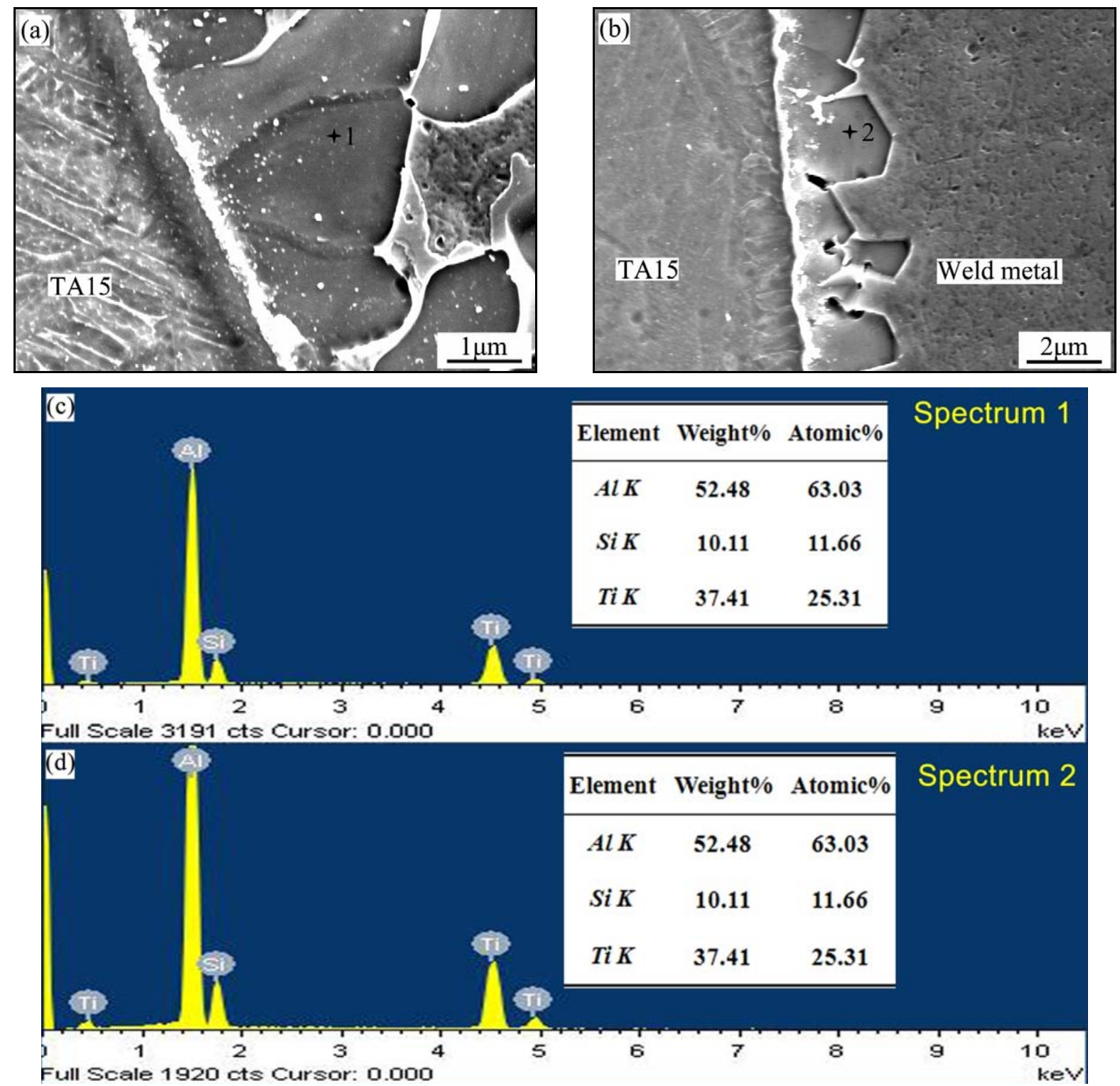

Fig. 6. EDS spot analysis near Ti/Al interface with ER4047 filler wire: (a) test location of spot 1; (b) test location of spot $2 ;$ (c) result of spot $1 ;$ (d) result of spot 2 .

titanium element has a low content. However, distribution trend of the aluminum element is opposite to that of titanium element. In serrated $\mathrm{TiAl}_{3}$ intermetallic compounds, the content of the aluminum element is relatively stable, and it appears platform on the distribution curve. The content of silicon near the interface is higher than that in base metal and weld metal, which indicates the uphill diffusion of silicon. The enrichment of silicon near the interface resulted in silicon replacing the lattice of aluminum in $\mathrm{TiAl}_{3}$ phase and forming $\operatorname{Ti}\left(\mathrm{Al}_{x} \mathrm{Si}_{1-x}\right)_{3}$, which is well in agreement with the report by $\mathrm{Ma}[9]$.

The formation of interfacial IMCs at high temperature was dependent on the reaction of alloying elements. Main alloying elements near the interface included titanium, aluminum, and silicon. According to the phase identification by the combined analysis of XRD and EDS, the possible reactions at the high temperature included the following:

$$
\begin{gathered}
\mathrm{Ti}+\mathrm{Si}=\mathrm{TiSi}, \\
5 \mathrm{Ti}+3 \mathrm{Si}=\mathrm{Ti}_{5} \mathrm{Si}_{3}, \\
\mathrm{Ti}+\mathrm{Al}=\mathrm{TiAl}, \\
\mathrm{Ti}+3 \mathrm{Al}=\mathrm{TiAl}_{3} .
\end{gathered}
$$

In the view of thermodynamics, Gibbs free energy of above reactions could be described by the following 

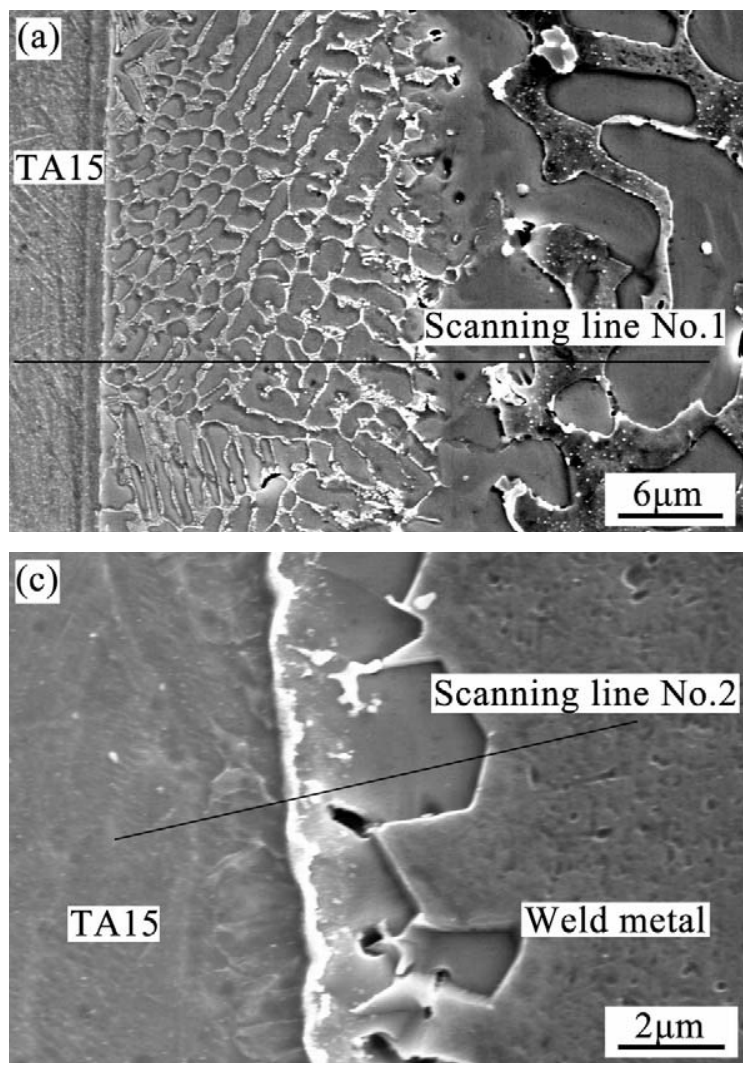

(b) HAZ $\downarrow$ Reaction layer , Weld metal

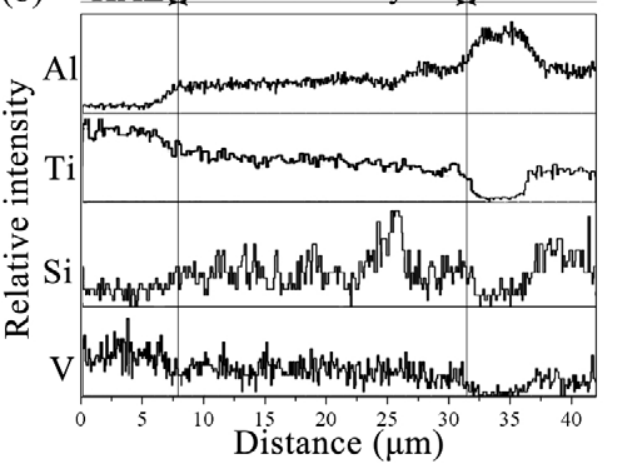

(d) $\quad \mathrm{HAZ} \downarrow \downarrow$ Interface $\downarrow$ Weld metal

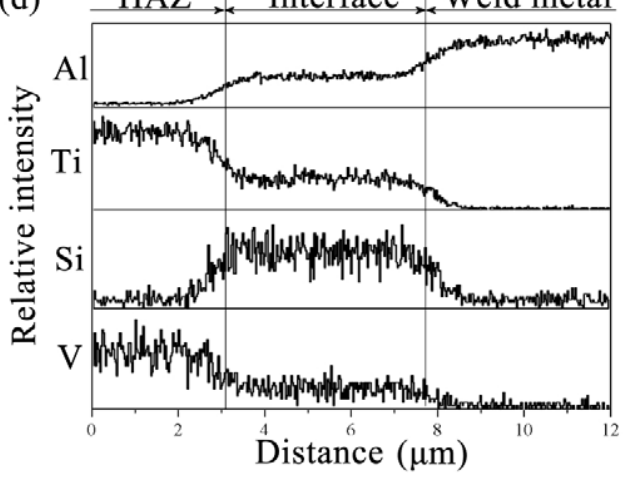

Fig. 7. EDS line scanning analysis near Ti/Al interface: (a) scanning location near the fusion-welding interface; (b) result of EDS scanning line No.1; (c) scanning location near the brazed interface; (d) result of EDS scanning line No. 2.

equation:

$$
\Delta G^{\circ}=\sum c_{\text {products }} G_{\text {products }}^{\circ}-\sum c_{\text {reactans }} G_{\text {reactans }}^{\circ}
$$

where $\Delta G^{\circ}$ is the Gibbs free energy of reaction, $c_{\text {products }}$ is the stoichiometric number of products in chemical reaction equation, $G^{\circ}$ products is the Gibbs free energy of products, $c_{\text {reactants }}$ is the stoichiometric number of reactants in chemical reaction equation, $G^{\circ}$ reactants is the Gibbs free energy of reactants. By the equation (2), the Gibbs free energy of possible reactions dependence of temperature was calculated, as shown in Fig. 8. With the temperature decreasing, the values of Gibbs free energy become negative which indicates the thermodynamical possibility for all above reactions to occur. However, the value of Gibbs free energy $\Delta G^{\circ}$ for forming $\mathrm{Ti}_{5} \mathrm{Si}_{3}$ is the lowest in all ranges of reaction temperature, which indicates that $\mathrm{Ti}_{5} \mathrm{Si}_{3}$ phase is the easiest to form [17]. So $\mathrm{Ti}_{5} \mathrm{Si}_{3}$ phase would be primarily formed near the interface. Also, the reaction (2) is extremely exothermic, and the heat could generate enough high temperature to increase the fluidity of liquid metal, which is conducive to spreading of liquid mixed metal on titanium alloy.

Effect of silicon on the fusion-welding interfacial reaction is different from that on the brazed inter-

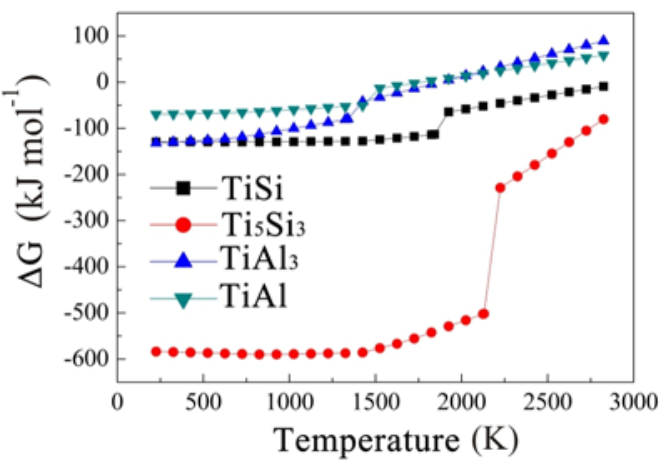

Fig. 8. Gibbs free energy of forming possible $\mathrm{Ti}-\mathrm{Al}(\mathrm{Si})$ intermetallic compounds verse temperature.

facial reaction. Therefore, two models were built to illuminate the effect of silicon on interfacial reactions. Fusion-welding interface zone was formed by interfacial reaction between molten titanium and liquid mixed metal. The effect of silicon on the fusionwelding interfacial reaction mechanism could be described as following steps:

1. Under the effect of arc blow force, liquid mixed metal with much heat spread on the titanium alloy, which facilitated the melting of titanium. Meanwhile, the alloying element atoms ( $\mathrm{Al}$ and $\mathrm{Si}$ ) diffused to- 

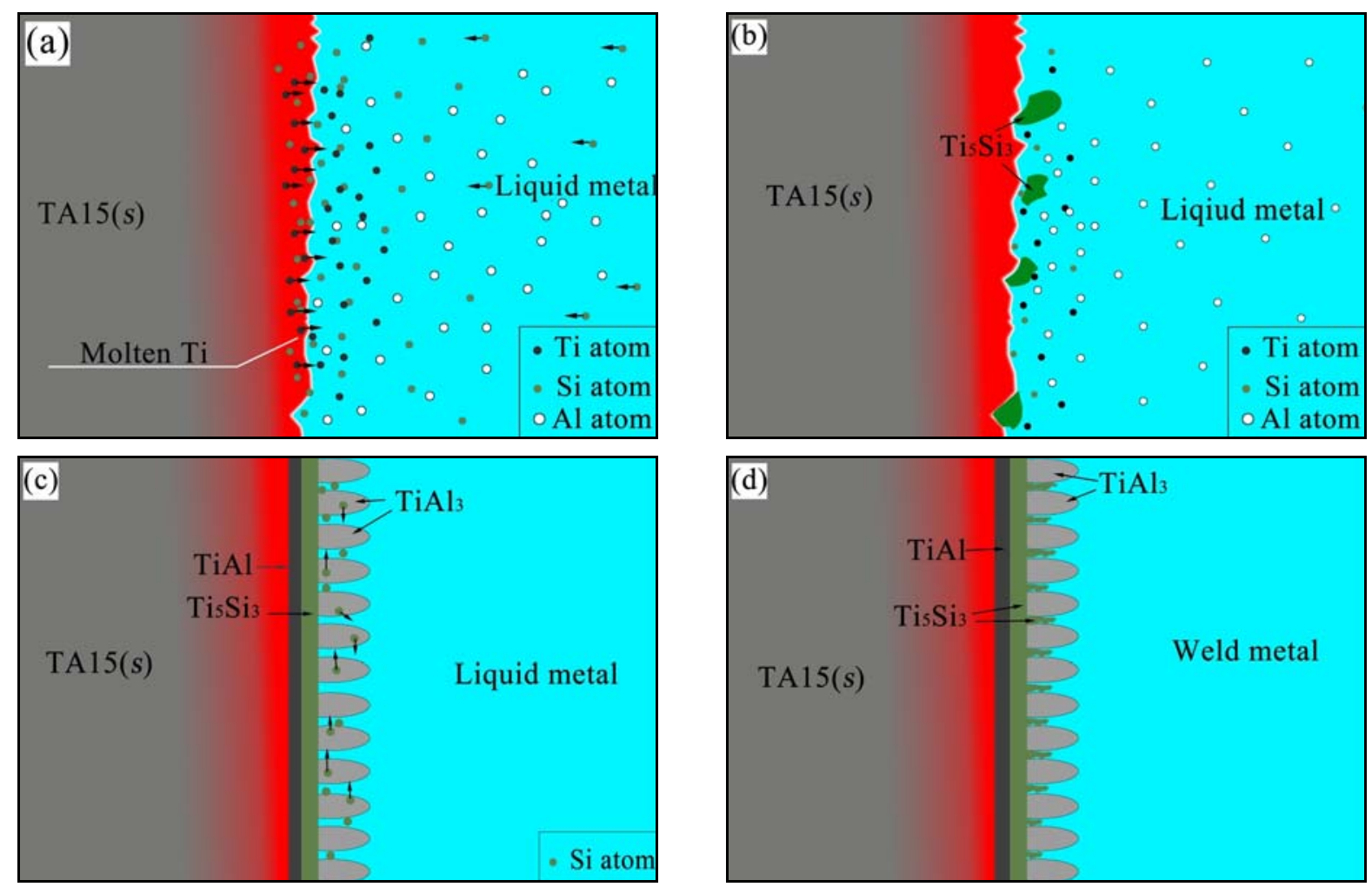

Fig. 9. Effect mechanism of $\mathrm{Si}$ on fusion-welding interface reaction: (a) titanium melting and atoms diffusion; (b) the formation of $\mathrm{Ti}_{5} \mathrm{Si}_{3}$ at high temperature; (c) the formation of TiAl layer and $\mathrm{Ti}_{5} \mathrm{Si}_{3}$ layer; (d) the formation of discontinuous $\mathrm{TiAl}_{3}$.
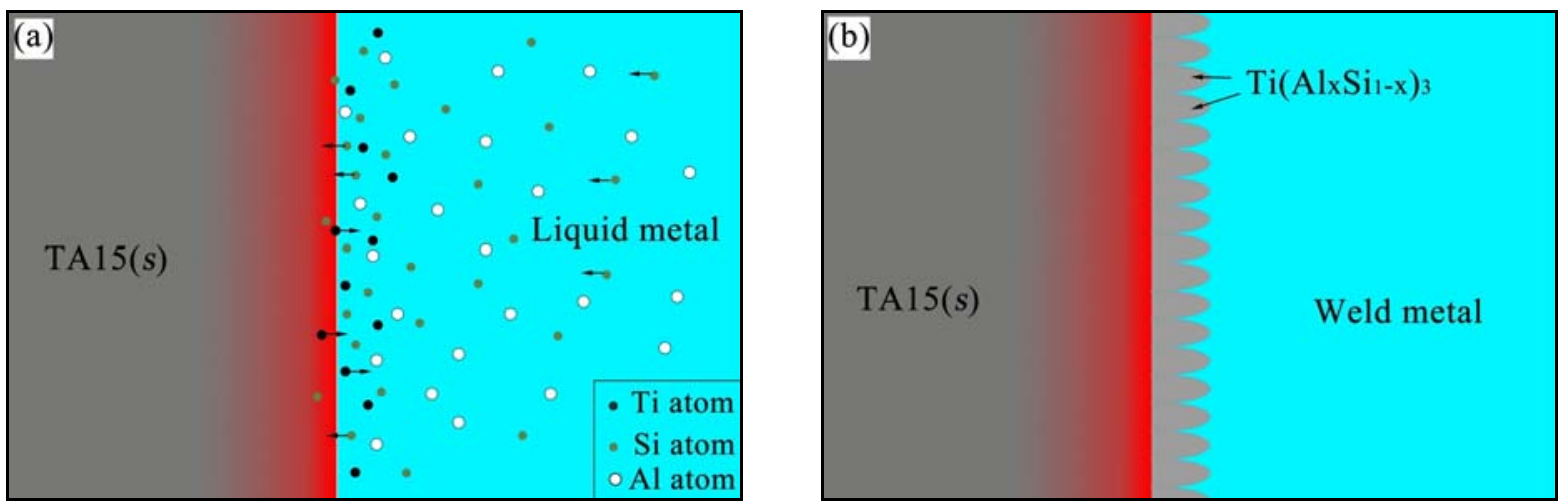

Fig. 10. Effect mechanism of $\mathrm{Si}$ on brazed interface reaction: (a) atoms diffusion; (b) the forming of $\mathrm{Ti}_{(}\left(\mathrm{Al}_{x} \mathrm{Si}_{1-x}\right)_{3} \operatorname{layer}_{\text {. }}$

ward the interface zone, and concentration gradient was formed, which is shown in Fig. 9a. Also, it should be taken into account that the molten titanium near the interface increased the concentration gradient and could provide a large driving force for atoms diffusing to the interface [18]. So alloying elements atoms enriching near the interface would react with each other intensely.

2. A mass of silicon enriched near the interface and the concentration of silicon reached a high level. At evaluated temperature, the Gibbs free energy of forming $\mathrm{Ti}_{5} \mathrm{Si}_{3}$ phase is lower than that of other phases. Therefore, the reaction took place: $\mathrm{L} \rightarrow \mathrm{Ti}_{5} \mathrm{Si}_{3}$ [19].
Small bulk $\mathrm{Ti}_{5} \mathrm{Si}_{3}$ phase was formed and floated near the interface, as shown in Fig. 9(b).

3. The forming of $\mathrm{Ti}_{5} \mathrm{Si}_{3}$ consumed some $\mathrm{Ti}$ atoms and suppressed more $\mathrm{Ti}$ atoms diffusing from base metal to weld metal. The numerous $\mathrm{Al}$ atoms gathered near the interface. With the decreasing of temperature, the following reaction occurred: $\mathrm{L} \rightarrow$ $\mathrm{Ti}_{5} \mathrm{Si}_{3}+\mathrm{TiAl}$. So the TiAl layer and $\mathrm{Ti}_{5} \mathrm{Si}_{3}$ layer were distributed orderly from titanium alloy to weld metal. With increasing of distance to the interface, the concentration of Al increased while the concentration of $\mathrm{Ti}$ decreased. The superlattice $\mathrm{TiAl}_{3}$ phase was formed as the third layer microstructure, as shown in 
Fig. 9c. During the growth of $\mathrm{TiAl}_{3}$, silicon element was expelled from the front of solid-liquid interface, especially between the $\mathrm{TiAl}_{3}$ columnar crystals.

4. The expelled $\mathrm{Si}$ between $\mathrm{TiAl}_{3}$ columnar crystals reacted with $\mathrm{Ti}$ to form finer $\mathrm{Ti}_{5} \mathrm{Si}_{3}$ phase, which contributed to the discontinuous distribution of $\mathrm{TiAl}_{3}$ phase along the interface [20], as shown in Fig. 9d. Moreover, interfacial layer microstructure was formed under the effect of silicon.

Effect of silicon on the brazing interfacial reaction is shown in Fig. 10. The mechanism of reactions was divided into the following two steps:

1. Due to the low heat input, most of titanium alloy was not molten. However, titanium atoms diffused into the liquid mixed metal at high temperature and alloying elements atoms also spread on the surface of titanium alloy, as shown in Fig. 10a.

2. Because of the short time at high temperature, there was no enough time for Si reacting with $\mathrm{Ti}$ to form $\mathrm{Ti}_{5} \mathrm{Si}_{3}$. During the solidification, as shown in Fig. 10b, a mass of Si was in the cluster of Ti-Al, so Si and $\mathrm{Al}$ simultaneously reacted with $\mathrm{Ti}$. In other words, Si took part in the following reaction: $\mathrm{Ti}+3(\mathrm{Al}, \mathrm{Si})=$ $\operatorname{Ti}\left(\mathrm{Al}_{x} \mathrm{Si}_{1-x}\right)_{3}$. The participation of $\mathrm{Si}$ also suppressed the growth of IMCs [21], so the thickness of brazed interface was thinner than that of the fusion-welding interface.

\section{Conclusions}

1. The Ti/Al joints using PCGTAW with filler wires containing silicon were improved, and the high content of silicon facilitated the spreading of liquid mixed metal on the surface of titanium alloy.

2. Interfacial morphologies are dependent on the heat distribution and the content of silicon. The $\mathrm{Ti} / \mathrm{Al}$ interface of PCGTAW joints has the fusion-brazed characteristics. The reaction layered microstructure near fusion-welding interface included $\mathrm{TiAl}, \mathrm{Ti}_{5} \mathrm{Si}_{3}$, and $\mathrm{TiAl}_{3}$. Moreover, the reaction layered microstructure near the brazed interface was mainly composed of $\operatorname{Ti}\left(\mathrm{Al}_{x} \mathrm{Si}_{1-x}\right)_{3}$.

3 . Silicon in the filler wires could react with titanium to form $\mathrm{Ti}_{5} \mathrm{Si}_{3}$ phase or $\mathrm{Ti}\left(\mathrm{Al}_{x} \mathrm{Si}_{1-x}\right)_{3}$ near the interface. The effect of silicon on the reaction mechanism of fusion-welding interface mainly included that the formation of $\mathrm{Ti}_{5} \mathrm{Si}_{3}$ consumed most molten titanium and suppressed the reaction of titanium with aluminum. Moreover, the $\mathrm{Ti}_{5} \mathrm{Si}_{3}$ distributing at the grain boundaries contributed to the forming of discontinuous $\mathrm{TiAl}_{3}$. The effect of silicon on the reaction mechanism of brazed interface mainly was reflected by the participation of silicon in the reaction of titanium with aluminum, which contributed to the forming of $\operatorname{Ti}\left(\mathrm{Al}_{x} \mathrm{Si}_{1-x}\right)_{3}$.

\section{Acknowledgements}

This project was supported by the National Natural Science Foundation of China (Grant No. 51575316).

\section{References}

[1] Kenevisi, M. S., Mousavi Khoie, S. M.: Mater. Des., 38, 2012, p. 19. doi:10.1016/j.matdes.2012.01.046

[2] Alhazaa, A. N., Khan, T. I.: J. Alloy. Compd., 494, 2010, p. 351. doi:10.1016/j.jallcom.2010.01.037

[3] Song, Z. H., Nakata, K. A., Wu, A. P., Liao, J. S.: Mater. Sci. Eng. A, 560, 2013, p. 111. doi:10.1016/j.msea.2012.09.044

[4] Dressler, U., Biallas, G., Alfaro Mercado, U.: Mater. Sci. Eng. A, 526, 2009, p. 113. doi:10.1016/j.msea.2009.07.006

[5] Ren, J. W., Li, Y. J., Feng, T.: Mater. Lett., 56, 2002, p. 647. doi:10.1016/S0167-577X(02)00570-0

[6] Wei, S. Z., Li, Y. J., Wang, J., Liu, K.: J. Mater. Eng. Perform., 23, 2014, p. 1451. doi:10.1007/s11665-014-0874-2

[7] Chen, X. G., Yan, J. C., Gao, F., Wei, J. H., Xu, Z. W., Fan, G. H.: Ultrason. Sonochem., 20, 2013, p. 144. doi:10.1016/j.ultsonch.2012.06.011

[8] Chen, S. H., Li, L. Q., Chen, Y. B., Huang, J. H.: J. Alloy. Compd., 509, 2011, p. 891. doi:10.1016/j.jallcom.2010.09.125

[9] Ma, Z. P., Wang, C. W., Yu, H. C., Yan, J. C., Shen, H. R.: Mater. Des., 45, 2013, p. 72. doi:10.1016/j.matdes.2012.09.007

[10] Chen, S. H., Li, L. Q., Chen, Y. B., Dai, J. M., Huang, J. H.: Mater. Des., 32, 2011, p. 4408. doi:10.1016/j.matdes.2011.03.074

[11] Liu, K., Li, Y. J., Wei, S. Z., Wang, J.: Mater. Manuf. Processes, 29, 2014, p. 969. doi:10.1080/10426914.2013.864414

[12] Wei, S. Z., Li, Y. J., Wang, J., Liu, K.: Kovove Mater., 52, 2014, p. 85.

[13] Padmanaban, G., Balasubramanian, V.: Met. Mater. Int., 17, 2011, p. 831. doi:10.1007/s12540-011-1022-2

[14] Rajkumar, V., Arivazhagan, N.: Mater. Des., 63, 2014, p. 69. doi:10.1016/j.matdes.2014.05.055

[15] Toshev, B. V., Platikanov, D.: Colloids Surf. A, 291, 2006, p. 177. doi:10.1016/j.colsurfa.2006.06.013

[16] Koopal, L. K.: Adv. Colloid Interface Sci., 179, 2012, p. 29. doi:10.1016/j.cis.2012.06.009

[17] Xiong, J. H., Huang, J. H., Zhang, H. Zhao, X. K.: Mater. Sci. Eng. A, 527, 2010, p. 1096. doi:10.1016/j.msea.2009.09.024

[18]. Zhang, P., Cai, Z. H., Xiong, W. Q.: Surf. Coat. Technol., 201, 2007, p. 6819. doi:10.1016/j.surfcoat.2006.09.119

[19] Fan, D. Y., Huang, J. H., Wang, Y. H., Chen, S. H., Zhao, X. K.: Mater. Sci. Eng. A, 617, 2014, p. 66. doi:10.1016/j.msea.2014.08.053

[20] Mirjalili, M., Soltanieh, M., Matsuura, K. Ohno, M.: Intermetallics, 32, 2013, p. 297. doi:10.1016/j.intermet.2012.08.017

[21] Takemoto, T., Okamoto, I.: J. Mater. Sci., 23, 1988, p. 1301. doi:10.1007/BF01154593 